\title{
Molecular Mechanisms of Congenital Heart Disease
}

\author{
Jing-bin Huang and Jian Liang \\ Department of Cardiothoracic Surgery, The Affiliated Ruikang \\ Hospital of Guangxi Traditional Chinese Medical College, Nanning
}

China

\section{Introduction}

Congenital heart disease (CHD) is the most common type of birth defect, affecting $1 \%$ of all live births, and is the leading non-infectious cause of death in the first year of life [1,2]. CHD is a multifactorial complex disease, with environmental and genetic factors playing important roles. It has been recognized that environmental factors/insults during fetal development increase the risk of CHD, including viral infections with rubella [3], exposure to chemical teratogens such as retinoic acid, lithium, dilantin [4]and halogenated hydrocarbon [5] and maternal diseases including diabetes and systemic lupus erythematosus $[1,6]$. Epidemiologic studies of CHD have demonstrated an increased recurrence risk for cardiac malformations in sequent pregnancies, supporting the existence of gene predispositions.

Great progress in molecular genetics and developmental biology has been made. Current genetic techniques for evaluation of congenital heart defects include cytogenetic techniques, fluorescence in situ hybridization (FISH) and DNA mutation analysis. Most methods employ polymerase chain reaction-based assays. Indirect screening methods, such as denaturing high-performance liquid chromatography or single-strand conformation polymorphism have been used extensively. More expensive exon-by-exon sequencing of genomic DNA has recently emerged [7, 8]. It has been accepted that the intricate process of cardiac morphogenesis is controlled by a network of highly conserved genetic and molecular pathways. The origins of CHD are diverse, such as abnormal chromosome structure (eg. duplication or deletion), gene mutations, single nucleotide polymorphisms, abnormal RNA, epigenetics and so on, and they are summarized in Figure 1.

In humans, heart development begins at 15 to 16 days of gestation with the migration of precardiac stem cells, in five steps:(1)migration of precardiac cells from the primitive streak and assembly of the paired cardiac crescents at the myocardial plate, (2) coalescence of the cardiac crescents to form the primitive heart tube, establishing the definitive heart, (3) cardiac looping, assurance of proper alignment of the future cardiac chambers, (4) septation and heart chambers formation, and (5) development of the cardiac conduction system and coronary vasculature [9-11]. The establishment of left-right asymmetry is very important to the normal development of heart [12, 13]. Secreted FGF, BMP, Nodal, and Wnt act as input signal of symmetric cardiac morphogenesis, BMP2, FGF8, Shh/Ihh, and Nodal function as positive regulators, whereas Wnt and Ser are negative regulators [14-16]. The cardiogenic 
plate-specific expressed genes NKX2.5, SRF, GATA4, TBX5, and HAND2, compose the core regulatory network of cardiac morphogenesis, controlling heart looping, left-right symmetry and chambers formation. SRF regulates the differentiation of coronary vascular smooth muscle cells $[17,18]$. Genes that involved in epicardial development include FOG-2, vascular cell adhesion molecule 1, integrins, erythropoietin, and erythropoietin receptor. Specific genes such as the NOTCH receptor, Jagged (JAG), WNT, transforming growth factor beta 2 (TGF 132 ) and bone morphogenic proteins have been implicated in cardiac neural crest development in the mouse[12, 19-21]. Retinoic acid signal pathway is involved in the regulation of cardiac looping. Complex signal pathways are implicated in the crosstalk between endocardium and myocardium to form endocardial cushion and heart valves, including VEGF, NFATc1, Notch, Wnt/B-catenin, BMP/TGF-B, EGF, erbB, NF1 signal pathways [10, 22-24].

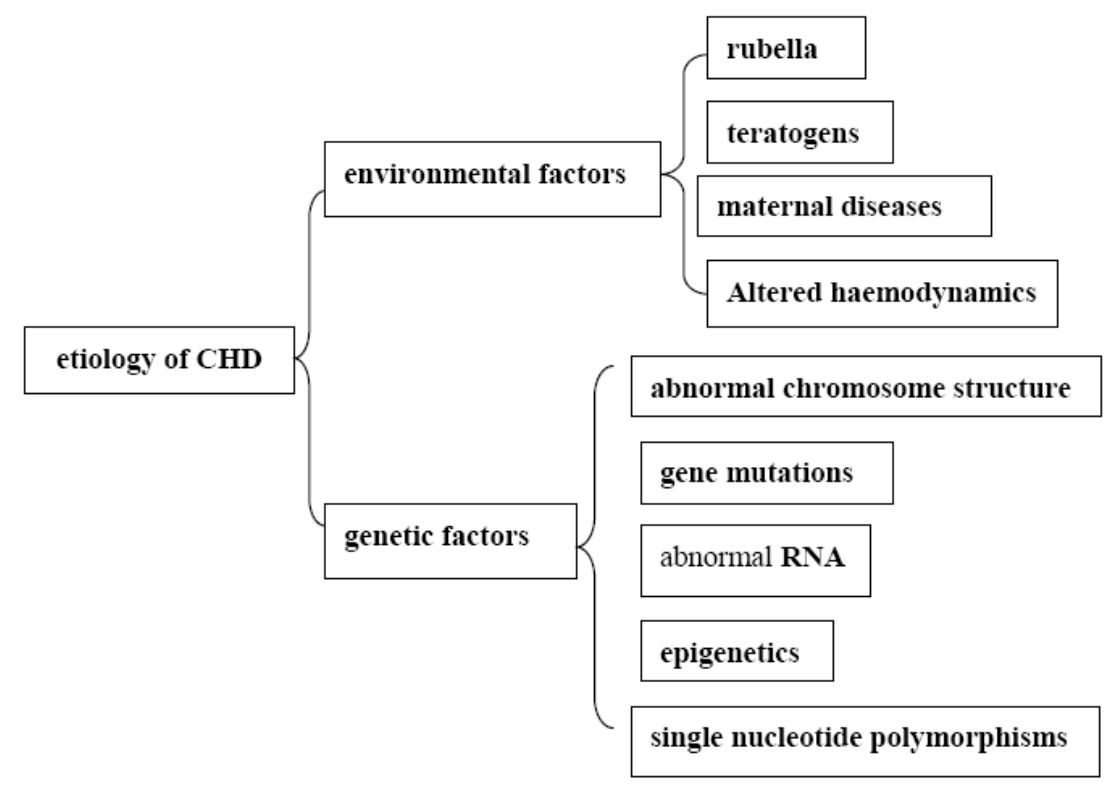

Fig. 1. Eteology of CHD

\section{Molecular mechanisms of congenital heart disease}

\subsubsection{Causative genes of $\mathrm{CHD}$}

The etiological factors of many genetic syndromes and familial CHD have been identified, but the genetic basis of majority of "sporadic" CHD remains unknown. With the progress in molecular genetics and developmental biology, many genes associated heart development have been identified. When searching computer databases such as NCBI Gene Bank for "cardiac or heart", we can indentify 1154 loci in human. Search for"(heart or cardiac)and development", limited to human, 630 genes were found. A number of selected congenital heart defects and genetic syndromes have been found to be associated with mutations in a variety of single genes. The mutations were found only in affected individuals, were not present in control samples, and were demonstrated to change protein structure or function. 
Disease genes of CHD identified to date are summarized in Table 1, and the functions of these causative genes are summarized as following [25].

\begin{tabular}{|c|c|c|}
\hline disorder & Causative genes & Chromosome Location \\
\hline \multicolumn{3}{|l|}{ Congenital heart defects } \\
\hline $\begin{array}{l}\text { Familial congenital heart } \\
\text { diseas(ASD, } \\
\text { atrioventricular block) }\end{array}$ & NKX2.5 & $5 q 34-q 35$ \\
\hline D-TGA, DORV & CFC1 & $2 q 21$ \\
\hline D-TGA & PROSIT240 & $12 \mathrm{q} 24$ \\
\hline \multirow{3}{*}{ Tetralogy of Fallot } & ZFPM2 & $8 \mathrm{q} 23$ \\
\hline & NKX2.5 & $5 q 34-q 35$ \\
\hline & $J A G 1$ & $20 p 12$ \\
\hline $\begin{array}{l}\text { Atrioventricular septal } \\
\text { defect }\end{array}$ & CRELD1 & $3 \mathrm{p} 21$ \\
\hline ASD/VSD & GATA4 & $8 \mathrm{p} 23$ \\
\hline \multirow[t]{4}{*}{ Heterotaxy } & ZIC3 & $X q 26$ \\
\hline & CFC1 & $2 q 21$ \\
\hline & $A C V R 2 B$ & 3p21.3-p221q42.1 \\
\hline & LEFTYA & \\
\hline $\begin{array}{l}\text { Supravalvar aortic } \\
\text { stenosis Syndromes }\end{array}$ & ELN & $7 q 11$ \\
\hline Holt-Oram Syndromes & TBX5 & $12 \mathrm{q} 24$ \\
\hline Alagille Syndromes & $J A G 1$ & 20p12 \\
\hline Char Syndromes (PDA) & TFAP2B & $6 \mathrm{p} 12$ \\
\hline \multirow[t]{3}{*}{ Noonan Syndromes } & PTPN11 & $12 q 24$ \\
\hline & KRAS & $2 \mathrm{p} 1.21$ \\
\hline & SOS1 & $2 \mathrm{p} 21$ \\
\hline CHARGE Syndromes & CHD7 & $8 \mathrm{q} 12$ \\
\hline Ellis-van Creveld & $E V C, E V C 2$ & $4 \mathrm{p} 16$ \\
\hline Marfan Syndromes & FBN1 & $15 q 21.1$ \\
\hline Marfan-like Syndromes & TGFBR2 & $3 p 22$ \\
\hline Cardiofaciocutaneous & KRAS & $12 \mathrm{p} 12.1$ \\
\hline \multirow[t]{3}{*}{ Syndromes } & $B R A F$ & $7 q 34$ \\
\hline & MEK1 & $15 q 21$ \\
\hline & MEK2 & $7 \mathrm{q} 32$ \\
\hline Costello Syndromes & HRAS & 11p15.5 \\
\hline
\end{tabular}

Table 1. Causative genes of CHD

For example, NKX2-5, Homeobox-containing genes play critical roles in regulating tissuespecific gene expression essential for tissue differentiation, as well as determining the temporal and spatial patterns of development. It has been demonstrated that a Drosophila 
homeobox-containing gene called 'tinman' is expressed in the developing dorsal vessel and in the equivalent of the vertebrate heart. Mutations in tinman result in loss of heart formation in the embryo, suggesting that tinman is essential for Drosophila heart formation. Furthermore, abundant expression of Csx, the presumptive mouse homolog of tinman, is observed only in the heart from the time of cardiac differentiation. CSX, the human homolog of murine Csx, has a homeodomain sequence identical to that of Csx and is expressed only in the heart, again suggesting that CSX plays an important role in human heart formation. Studies have recently shown that nonsyndromic CHD can result from single-gene defects. Schott et al identified mutations in NKX2.5 in 4 kindreds with atrial septal defects and atrioventricular conduction delay without other apparent syndromic features. The mutations were found only in affected individuals, were not present in control samples, and were demonstrated to change protein structure or function [26-28].

Noonan Syndrome is a genetic multiple malformation disorder that includes short stature, typical facial dysmorphism, webbed neck, chest deformity, and cardiovascular abnormalities. The cardiac involvement is observed in $80 \%$ to $90 \%$ of affected individuals, with valvar pulmonic stenosis and hypertrophic cardiomyopathy being the most common. Other congenital heart defects observed in Noonan Syndrome are secundum atrial septal defect, atrioventricular septal defect, mitral valve abnormalities, aortic coarctation, and tetralogy of Fallot. Noonan Syndrome is genetically heterogeneous, which means that there are at least 3 Noonan Syndrome disease genes, PTPN11, SOS1, and KRAS [29]. It is PTPN11, which encodes a protein tyrosine phosphatase called SHP-2. SHP-2 plays an important role in signal transduction for a wide variety of biological processes, including the formation of the semilunar valves. Mutations in the PTPN11 gene are observed in $40 \%$ to $50 \%$ of Noonan Syndrome patients $[25,30]$.

\subsubsection{Functions of the causative genes of CHD}

Table2 shows the functions of the causative genes of CHD.

\begin{tabular}{lll}
\hline Genes affected & & \\
\hline Transcription factors & Signaling proteins & Vascular extracellular matrix \\
GATA4 & PTPN11 & FBN-1 \\
TBX1 & Jagged 1 & Elastin \\
TBX5 & DMPK & \\
NKX2.5 & CFC1 & \\
dHAND & SOS1 & \\
TFAP2 & TGFBR2 & \\
ZFPM2 & KRAS & \\
& BRAF & \\
& MEK1 & \\
& MEK2 & \\
& HRAS & \\
& ACVR2B & \\
& CRELD1 & \\
& LEFTYA & \\
\hline
\end{tabular}

NKX2-5, NK2 transcription factor related, locus 5

Table 2. Inborn Errors Causing CHD 
Homeobox-containing genes play critical roles in regulating tissue-specific gene expression essential for tissue differentiation, as well as determining the temporal and spatial patterns of development. Mutations in NKX2-5 result in loss of heart formation in the embryo, suggesting that NKX2-5 is essential for heart formation [31, 32].

CFC1, cripto, FRL-1, cryptic family 1

This gene encodes a member of the epidermal growth factor (EGF)- Cripto, Frl-1, and Cryptic (CFC) family. These proteins play key roles in intercellular signaling pathways during vertebrate embryogenesis. Mutations in this gene can cause autosomal visceral heterotaxy. This protein is involved in left-right asymmetric morphogenesis during organ development [33, 34].

PROSIT240, MED13L, mediator complex subunit 13-like

Also known as THRAP2, The evolutionarily conserved THRAP genes encode a family of proteins that regulate embryonic development. THRAP2 is involved in early development of the heart and brain [35].

ZFPM2, zinc finger protein, multitype 2

The zinc finger protein encoded by this gene is a widely expressed member of the FOG family of transcription factors. The family members modulate the activity of GATA family proteins, which are important regulators of hematopoiesis and cardiogenesis in mammals [36].

Jagged 1, jagged 1 (Alagille syndrome)

The jagged 1 protein encoded by JAG1 is the human homolog of the Drosophilia jagged protein. Human jagged 1 is the ligand for the receptor notch 1. Mutations that alter the jagged 1 protein cause Alagille syndrome [37].

CRELD1, cysteine-rich with EGF-like domains 1

Epidermal growth factor-like repeats are a class of cysteine-rich domains that mediate interactions between proteins of diverse function. CRELD1 is the founding member of a family of matricellular proteins [38].

GATA4, GATA binding protein 4

This gene encodes a member of the GATA family of zinc-finger transcription factors. This protein is thought to regulate genes involved in embryogenesis and in myocardial differentiation and function. Mutations in this gene have been associated with cardiac septal defects [39].

ZIC3, Zic family member 3 heterotaxy 1

This gene encodes a member of the ZIC family of C2H2-type zinc finger proteins. Mutations in this gene cause $X$-linked visceral heterotaxy [40].

ACVR2B, activin A receptor, type 2, beta

Activins are dimeric growth and differentiation factors which belong to the transforming growth factor-beta superfamily of structurally related signaling proteins. These receptors are all transmembrane proteins [41]. 
LEFTYA, left-right determination factor 2

This gene encodes a member of the TGF-beta family of proteins. The encoded protein is secreted and plays a role in left-right asymmetry determination of organ systems during development.Mutations in this gene have been associated with left-right axis malformations, particularly in the heart and lungs [42].

ELN, Elastin

This gene encodes a protein that is one of the two components of elastic fibers. Deletions and mutations in this gene are associated with supravalvular aortic stenosis (SVAS) and autosomal dominant cutis laxa [43].

TBX5, T-box 5

This gene is a member of a phylogenetically conserved family of genes that share a common DNA-binding domain, the T-box. The encoded protein may play a role in heart development and specification of limb identity. Mutations in this gene have been associated with Holt-Oram syndrome [44].

TFAP2B, transcription factor AP-2 beta

This gene encodes a member of the AP-2 family of transcription factors. This protein functions as both a transcriptional activator and repressor. Mutations in this gene result in autosomal dominant Char syndrome, suggesting that this gene functions in the differentiation of neural crest cell derivatives [45].

PTPN11, protein tyrosine phosphatase, non-receptor type 11

The protein encoded by this gene is a member of the protein tyrosine phosphatase (PTP) family. PTPs are known to be signaling molecules that regulate a variety of cellular processes including cell growth, differentiation, mitotic cycle, and oncogenic transformation. Mutations in this gene are a cause of Noonan syndrome as well as acute myeloid leukemia [46].

SOS1, son of sevenless homolog 1

This gene encodes a protein that is a guanine nucleotide exchange factor for RAS proteins, membrane proteins that bind guanine nucleotides and participate in signal transduction pathways. Mutations in this gene are associated with gingival fibromatosis 1 and Noonan syndrome type 4 [47].

CHD7, chromodomain helicase DNA binding protein 7

This gene encodes a protein that contains several helicase family domains. Mutations in this gene have been found in some patients with the CHARGE syndrome [48, 49].

EVC, Ellis van Creveld syndrome

This gene encodes a protein containing a leucine zipper and a transmembrane domain. This gene has been implicated in both Ellis-van Creveld syndrome (EvC) and Weyers acrodental dysostosis [50].

FBN1, fibrillin 1

This gene encodes a member of the fibrillin family. Mutations in this gene are associated with Marfan syndrome, isolated ectopia lentis, autosomal dominant Weill-Marchesani syndrome, MASS syndrome, and Shprintzen-Goldberg craniosynostosis syndrome [51]. 
TGFBR2, transforming growth factor receptor 2

This gene encodes a member of the Ser/Thr protein kinase family and the TGFB receptor subfamily. Mutations in this gene have been associated with Marfan Syndrome, Loeys-Deitz Aortic Aneurysm Syndrome, and the development of various types of tumors [52].

KRAS, v-Ki-ras2 Kirsten rat sarcoma viral oncogene homolog

This gene, encodes a protein that is a member of the small GTPase superfamily. The transforming protein that results is implicated in various malignancies, including lung adenocarcinoma, mucinous adenoma, ductal carcinoma of the pancreas and colorectal carcinoma [53].

BRAF, v-raf murine sarcoma viral oncogene homolog B1

This gene encodes a protein belonging to the raf/mil family of serine/threonine protein kinases. This protein plays a role in regulating the MAP kinase/ERKs signaling pathway, which affects cell division, differentiation, and secretion. Mutations in this gene are associated with cardiofaciocutaneous syndrome [53].

MEK1, MAP2K1, mitogen-activated protein kinase 1

The protein encoded by this gene is a member of the dual specificity protein kinase family, which acts as a mitogen-activated protein (MAP) kinase kinase. This kinase is involved in many cellular processes such as proliferation, differentiation, transcription regulation and development [54].

MEK2, MAP2K2, mitogen-activated protein kinase 2

The protein encoded by this gene is a dual specificity protein kinase that belongs to the MAP kinase kinase family. This kinase is known to play a critical role in mitogen growth factor signal transduction. Mutations in this gene cause cardiofaciocutaneous syndrome (CFC syndrome) [55].

HRAS, v-Ha-ras Harvey rat sarcoma viral oncogene homolog

This gene belongs to the Ras oncogene family. The products encoded by these genes function in signal transduction pathways. Mutations in this gene cause Costello syndrome. Defects in this gene are implicated in a variety of cancers [56].

\subsection{Pathogenic mechanisms of congenital heart disease}

Phenotypes of CHD vary from small ASD and VSD, which may go undetected throughout life, to large ASD and VSD, which are significantly symptomatic. Clinically significant anomalies range from persistence of fetal circulation (eg, patent ductus arteriosus) to complex defects such as transposition of the great vessels, single ventricle anomaly, hypoplastic left heart syndrome, and complex variants of heterotaxy. The etiological factors of many genetic syndromes and familial CHD have been identified, but the genetic basis of majority of "sporadic" CHD remains unknown. It is hypothesized that susceptibility resulted from single nucleotide polymorphisms or key gene(s), with the interaction of environmental factors, which disturb normal cardiac development, result in cardiac defects. There are six causative mechanisms according to pathogenetic classification of congenital cardiovascular malformations: ectomesenchymal tissue migration abnormalities (causing conotruncal malformations and aortic arch anomalies); intracardiac blood flow defects 
(causing septal defects and left or right heart obstructive malformations); cell death abnormalities (causing septal defects and valve abnormalities); extra cellular matrix abnormalities (causing atrioventricular canal defects); abnormal targeted growth (causing partial or total anomalous pulmonary venous return and cor triatriatum); and abnormal situs and looping (causing left-right positioning problems) [57, 58].

\subsubsection{Mutations in components of the cardiac gene network cause CHD}

Heart development is controlled by a highly conserved network of transcription factors that connect signaling pathways with genes of muscle growth, patterning, and contractility. The core transcription factor network consists of NKX2, MEF2, GATA, TBX, and Hand. Dozens of other transcription factors contribute to cardiogenesis, in many cases by serving as accessory factors for these core regulators. Autoregulatory and cross regulatory of the cardiac gene network maintain the cardiac phenotype once the network has been activated by upstream inductive signals. Mutations in components of the cardiac gene Network cause CHD [59, 60].

Mutations in NKX2.5 cause a spectrum of congenital heart defects, including atrial-septal defects (ASDs), ventricular-septal defects (VSDs), and cardiac conduction abnormalities. Mutations in TBX5 cause the congenital disease Holt-Oram syndrome, which is characterized by truncations of the upper limbs and heart malformations [61,62]. Mutations in GATA4, some of which disrupt its interaction with TBX5, cause ASDs and VSDs. In mouse models, haploinsufficiency for $\mathrm{Nkx} 2-5$ or Tbx 5 resulted in an increased incidence of structural heart disease, confirming that normal heart development is sensitive to small changes in expression levels of Nkx2-5 and Tbx5. GATA4 also is an essential, dosagedependent regulator of cardiac morphogenesis. The missense mutation in Gata4 specifically disrupted the Gata4-Tbx5 interaction while maintaining its ability to interact with Nkx2.5. In previous studies, Tbx5 had been shown to interact with $\mathrm{Nkx} 2.5$, demonstrating that all three transcription factors could physically interact in vitro. In summary, a mutation in any of these three genes can result in human CSD and suggests that these three genes may work to direct common molecular pathways critical for cardiac septum formation. [63, 64]. Consistent with this, mutations in $M Y H 6$, a downstream transcriptional target of GATA4 and TBX5, was implicated as a cause of human atrial septal defects .TBX5, GATA4 and NKX2-5 function together only to activate genes. The overlapping expression patterns and complex interactions of these transcription factors allow fine regulation of cardiac gene expression and morphogenesis [20, 65-67] (Figure 2).

\subsubsection{Regulatory pathway of cardiac genes}

Several types of congenital heart disease involve valve defects of varying severity. Notch signaling is an ancient intercellular signaling mechanism that plays an important role during valve development. Mutations affecting signaling proteins and downstream pathways can lead to valve disease. In mammals, four Notch family receptors have been described: NOTCH1 through to NOTCH4 [20, 68]. The Notch ligands are encoded by the Jagged (JAG1 and JAG2) and Delta-like (DLL1, DLL3 and DLL4) gene families. The Notch signaling pathway is an evolutionarily conserved mechanism used by metazoans to control cell fate decisions through local cell interactions. The notch gene encodes a single-pass transmembrane protein receptor that interacts with its ligands, Delta and Serrate/Jagged. Upon binding of the ligand, the intracellular domain of Notch (NIC) undergoes proteolytic cleavage, and is translocated to the nucleus. In the nucleus, NIC binds to its major downstream effector, Suppressor-of- 
Hairless $(\mathrm{Su}(\mathrm{H}))$. $\mathrm{Su}(\mathrm{H})$ binds to the regulatory sequences of the Enhancer-of-Split locus, upregulating the expression of basic helix-loop-helix proteins, which in turn regulate the expression of downstream target genes. Upon ligand binding, a signal is transmitted intracellularly by a process involving the proteolytic cleavage of the receptor and the subsequent nuclear translocation of the Notch intracellular domain (NICD) (Figure 3 ). Alagille syndrome is an autosomal dominant disorder characterized by developmental abnormalities of the liver, heart, eye, skeleton and, at lower penetrance, several other organs. Most cases of Alagille syndrome are caused by JAG1 mutations, although a small number of Alagille syndrome patients with $\mathrm{NOTCH} 2$ mutations have been identified. The cardiac defects associated with Alagille syndrome include pulmonary artery stenosis and hypoplasia, pulmonic valve stenosis, and tetralogy of Fallot. These defects are likely to be due to a requirement for Notch signaling-mediated differentiation of cardiac neural crest cells into smooth muscle cells, which has been demonstrated in a mouse model. Bicuspid aortic valve affects $1-2 \%$ of the population, making it the most common congenital cardiac malformation. Bicuspid aortic valve predisposes one to aortic valve calcification. Aortic valve calcification was linked to Notch regulation of the transcription factor RUNX2.Heterozygous mutations in the NOTCH1 gene were found in two families with autosomal-dominant aortic valve disease. NOTCH1 mutations are also found in $4 \%$ of sporadic bicuspid aortic valve patients. The formation of bicuspid aortic valve might reflect the role of Notch signaling in regulating the epithelial-mesenchymal transition required for the generation of the heart valves [20, 69, 70]. Recently, mutations in Notch1 in humans have been shown to cause aortic valve defects and activation of Notch1 in mouse leads to abnormal cardiogenesis characterized by deformities of the ventricles and atrioventricular canal. Additionally, mutations in various Notch signaling pathway genes, including Jagged1, mind bomb 1, Hesr1/Hey1, and Hesr2/Hey2, result in cardiac defects, such as pericardial edema, atrial and ventricular septal defects, cardiac cushion, and valve defects [71-74].

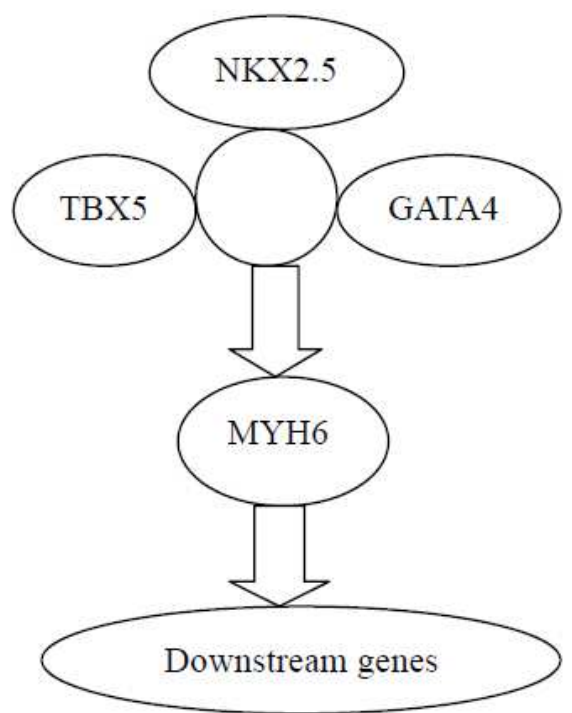

Fig. 2. Interaction of NKX2.5,TBX5 and GATA4 

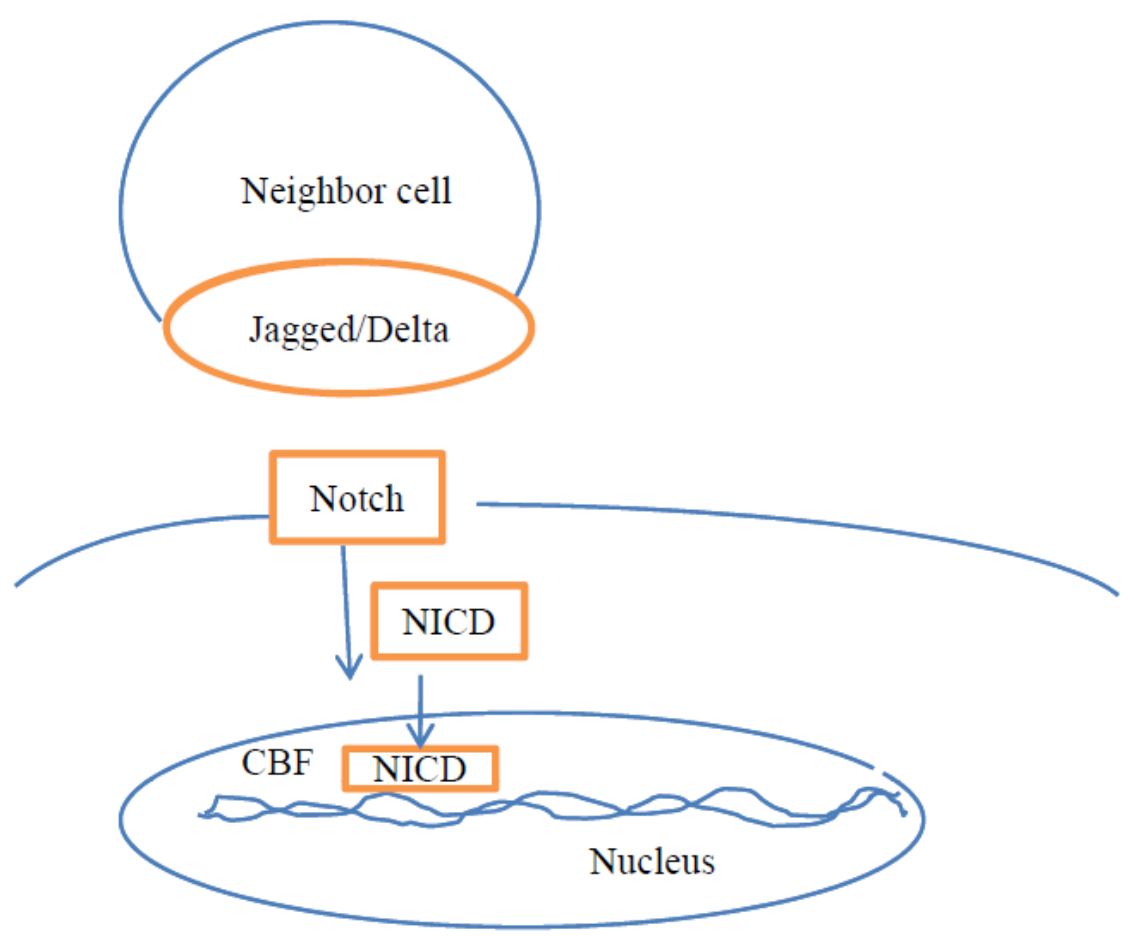

Fig. 3. Notch pathway

\subsubsection{Altered haemodynamics}

Haemodynamic forces have been demonstrated to play an important role in cardiac development. When these forces are impaired or when genes involved in growth and differentiation are not functioning correctly, malformations may arise. Shear stress is one of those haemodynamic forces, and the expression of many genes, including those of the endothelin pathway, changes in response to alterations in shear stress. For example, ligating the right lateral vitelline vein of chicken embryos results in cardiovascular malformations similar to those observed in knockout mice studies of components of the endothelin1/endothelin-converting enzyme-1/ endothelin-A receptor pathway. In zebrafish, altering haemodynamics mechanically or genetically has profound consequences on heart morphology. In mice, a recent study pinpointed altered haemodynamics as a key intermediate between altered outflow tract morphogenesis and signaling events in branchial-arch artery remodeling. In human, complex congenital heart diseases with an outflow tract defect, such as tetralogy of Fallot, can be accompanied by 'accessory' congenital heart diseases, such as persistent right-sided aortic arch. Because the heart functions during its morphogenesis, haemodynamic forces might participate in cardiac morphogenesis [20, 71, 74] (Figure 4). 


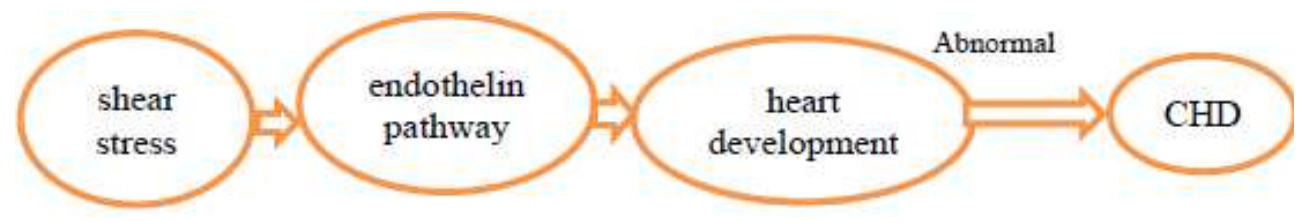

Fig. 4. Altered haemodynamics leads to CHD

\subsubsection{MicroRNA dysfunction}

MicroRNAs are natural, single-stranded, non-protein-coding small RNA molecules $(\sim 22$ nucleotides) that regulate gene expression by binding to target mRNAs and suppress its translation or initiate its degradation. Mature miRNAs are processed from -70 nucleotides long precursor miRNA (pre-miRNAs) that form hairpin secondary structures and that are often evolutionarily conserved. Pre-miRNAs are transcribed from miRNA genes. Although the specific biological roles of most miRNAs are still unknown, functional characterizations of a few of them suggest that these small RNA molecules are involved in many processes of animal development and physiology[75-77] .For example, miR-1 and miR-133 control cardiac and skeletal muscle development [78, 79]. Both genes are under the control of serum response factor, indicating that they are part of a developmental programme regulated by cardiac transcription factors. It has been shown that miR-1 targets the cardiac transcription factor HAND2. Deletion of miR-1-2 results in heart defects that include VSDs; surviving mice have conduction system defects and increased cardiomyocyte proliferation. Dysregulation of miRNAs might result in congenital heart disease in human [80, 81](Figure 5).

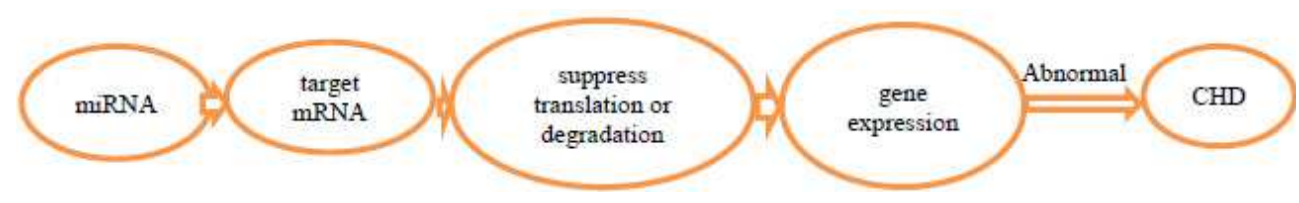

Fig. 5. MicroRNA dysfunction results in CHD

\subsubsection{Epignetics}

Epigenetics refers to DNA and chromatin modifications that play a critical role in regulation of various genomic functions, and it was then redefined as the study of heritable traits that are not dependent on the primary sequence of DNA. Although the genotype of most cells of a given organism is the same (with the exception of gametes and the cells of the immune system), cellular phenotypes and functions differ radically, and this can be (at least to some extent) controlled by differential epigenetic regulation that is set up during cell differentiation and embryonic morphogenesis $[82,83]$. Once the cellular phenotype is established, genomes of somatic cells are 'locked' in tissue-specific patterns of gene expression, generation after generation. This heritability of epigenetic information 
in somatic cells has been called an 'epigenetic inheritance system' [84]. Even after the epigenomic profiles are established, a substantial degree of epigenetic variation can be generated during the mitotic divisions of a cell in the absence of any specific environmental factors. Such variation is most likely to be the outcome of stochastic events in the somatic inheritance of epigenetic profiles. From the epigenetic point of view, phenotypic differences in monozygous twins could result, in part, from their epigenetic differences. It has recently become clear that epigenetic regulators play crucial roles in the global shaping and maintenance of developmental patterning. This involves dynamic tissue and cell type-specific changes during patterning, as well as the maintenance of the cellular memory that is required for developmental stability.BAF60C (also known as SMARCD3), a subunit of the Swi/Snf-like chromatin-remodelling complex BAF, physically links cardiac transcription factors to the BAF complex. Loss of BAF60C results in severe defects in cardiac morphogenesis and impaired activation of a subset of cardiac genes. The muscle-restricted histone methyltransferase SMYD1 (also known as BOP) is a crucial regulator of cardiac chamber growth and differentiation. Histone deacetylases have mostly been characterized as having an important role in heart hypertrophy and development [20] (Figure 6).

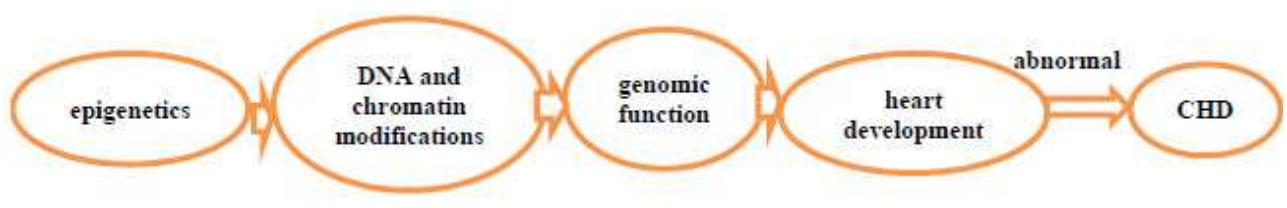

Fig. 6. Dysfunctions of epignetics leads to CHD

\subsubsection{Adult congenital heart diseases}

Individuals with congenital heart disease can suffer from secondary heart disease later in life, possibly as a result of corrective surgery during infancy. The sequelae are sometimes severe; for example, after closure of a septal defect, some patients can progress to heart failure. With improved surgical outcomes for those with congenital heart disease, the number of adults with such diseases now exceeds the number of children. The population of patients with adult congenital heart disease is approximately 800,000 in the U.S.A majority faces a lifetime of problems including arrhythmias, ventricular dysfunction, and one or more re-operations. Thus, it has become imperative to understand the postnatal consequences of congenital heart diseases [85]. Recent results suggest that these might be caused, at least in part, by the direct effects of mutations associated with congenital heart disease on postnatal heart morphology and function. For example, in a family with GATA4 mutations, apart from having heart structural defects, some individuals developed dilated cardiomyopathy later in life. Indeed, data from mouse models support a connection between GATA4 mutations and adult cardiomyopathy [86]. Similarly, mutations in TBX20 were identified in patients with cardiomyopathy as well as in those with structural congenital heart diseases. Mouse studies have also revealed roles for other congenital-heartdisease-associated genes in cardiac function. Studies of mice in which Nkx2-5 had been deleted only in the ventricles suggest a role for this gene in the function of the postnatal conduction system and in myocardial structure, and examination of patients with NKX2-5 
mutations revealed that some had aspects of cardiomyopathy, as predicted from the mouse data. Thus, embryonic patterning genes control structural components of the heart and can also have a separate role in heart function, for example by regulating Serca2.These genes can thus modulate important aspects of heart function that cause pathology in the postnatal heart when dysregulated. This concept has important implications for the clinical management of adults with congenital heart disease [20,87].

\section{Strategies and future perspectives}

The molecular mechanisms of congenital heart defects are so complex that we have to use diverse strategies to explore them. Animal Models Biomedical models have been defined as "surrogates for a human being, or a human biologic system, that can be used to understand normal and abnormal function from gene to phenotype and to provide a basis for preventive or therapeutic intervention in human diseases" . Because of the striking homology between mammalian genomes and the many similarities in anatomy, cell biology, and physiology, rat is an excellent animal model for studying of cardiac development and identifying novel genes that could contribute to human disease. The Human Genome Initiative is providing genetic information not only from humans, but also from animals traditionally used as models. In addition, related enabling technologies in transgenesis and animal cloning provide new approaches for designing and performing experiments to dissect complex biological systems. Because of these new technologies (e.g., transgenesis), scientists are no longer limited to the traditional methods of choosing naturally occurring models. Researchers can utilize genomic knowledge and available tools to create appropriate animal models. This approach is referred to as reverse genetics. In contrast to forward genetics in which the gene or genes responsible for a particular phenotype are identified by positional cloning (phenotype to genotype), the reverse genetics approach determines the function of a gene and predicts the phenotype of a cell, tissue, or organism (genotype to phenotype). Genome-Wide Studies Considerable progress has been made in understanding the pathophysiology of perioperative stress responses and their impact on the cardiovascular system; however, researchers are just beginning to unravel genetic and molecular determinants that predispose to increased risk for CHD. Recent improvements in genotyping technology and in our knowledge of human genetic variation have made it possible to carry out genome-wide genetic association studies to identify susceptibility genes for common disease. Multistage designs involving large numbers of coding sequence variants $(300,000)$ and relatively large samples sizes (several hundred cases and control subjects) will be essential to reliably detect alleles with appreciable effect sizes (2-fold increase in relative risk). Direct sequencing of candidate genes in cases and control subjects provides an alternative approach that can reveal low-frequency alleles that influence disease susceptibility [88,89]. Gene Expression (Microarrays) Microarray analysis is a useful tool to obtain a gene expression profile of CHD. However, current estimates suggest that greater than $60 \%$ of human genes have more than one isoform. Alternatively, spliced isoforms from the same gene can produce proteins with different properties and distinct functions. The specific roles of gene expression and their splicing variants necessary for development need to be further delineated. MicroRNA Current research has revealed that the influence of RNA molecules on gene expression reaches beyond the realm of protein synthesis back into the nucleus, where it not only dictates the transcriptional activity of genes, but also shapes 
the chromatin architecture of extensive regions of DNA. Non-coding RNA, in the context of this review, refers to transcripts expressed and processed in the nucleus much like any protein coding gene, but lacking an open reading frame and often transcribed antisense to bona fide protein coding genes. Dysregulation of miRNAs might result in congenital heart disease in humans. Further studies of miRNAs in CHD are required. Epigenetics There is increasing evidence that epigenetic modifications, arising primarily through DNA methylation and histone modifications may have as important a role as genetics in certain diseases, such as cancer, birth defects, developmental disorders, and psychiatric disorders. Bioinformatics Unprecedented growth in the interdisciplinary domain of biomedical informatics reflects the recent advancements in genomic sequence availability, high-content biotechnology screening systems, as well as the expectations of computational biology to command a leading role in drug discovery and disease characterization. These forces have moved much of life sciences research almost completely into the computational domain. Human genome project has succeeded, and postgenome era is following. Human genome comprises 30, 000-40, 000 genes, but their functions, relation, interaction, and regulation remain unknown. Bioinformatics is a powerful and indispensable tool in exploring the molecular mechanisms of CHD [90, 91].

\section{Conclusions}

Congenital heart disease (CHD) is the most common type of birth defect. Despite of the many advances in our understanding of cardiac development and many genes related to cardiac development identified, the fundamental etiology for the majority of cases of congenital heart disease remains unknown. CHD is a multifactorial complex disease, with environmental and genetic factors playing important roles. A number of causative genes of selected congenital heart defects and genetic syndromes have been found. The molecular mechanisms of CHD may include mutations in components of the cardiac gene network, altered haemodynamics, regulatory pathway of cardiac genes, microRNA dysfunction, epignetics, adult congenital heart diseases and so on. The molecular basis of CHD is an exciting and rapidly evolving field. The continuing advances in the understanding of the molecular mechanisms of CHD will hopefully result in improved genetic counseling and care of affected individuals and their families.

\section{Acknowledgements}

This study was supported by the Ruikang Hospital Natural Science Foundation (code: ZKZ201001).

\section{Abbreviations}

$\mathrm{ASD}=$ atrial septal defect; VSD= ventricular septal defect; $\mathrm{CSD}=$ cardiac septal defect; $\mathrm{SRF}=$ serum response factor (c-fos serum response element-binding transcription factor); $\mathrm{FGF}=$ fibroblast growth factor; $\mathrm{BMP}=$ bone morphogenetic protein; Nodal= nodal homolog; Wnt= wingless-type MMTV integration site family; Shh= sonic hedgehog homolog; Ihh= Indian hedgehog homolog; VEGF= vascular endothelial growth factor; NFATc1= nuclear factor of activated T-cells, cytoplasmic, calcineurin-dependent $1 ; ß$-catenin= catenin 
(cadherin-associated protein), beta 1 ; TGF- $\beta=$ transforming growth factor, beta 1 ; EGF= epidermal growth factor (beta-urogastrone) ; erbB= v-erb-b2 erythroblastic leukemia viral oncogene homolog 2, neuro/glioblastoma derived oncogene homolog; NF1= neurofibromin $1 ; \mathrm{MEF} 2=$ myocyte enhancing factor $2 ; \mathrm{Hand}=$ transcription factor protein; RUNX2= runt related transcription factor 2; NOTCH= Notch homolog; Hesr1/Hey1= hairy/enhancer-ofsplit related with YRPW motif $1 ; \mathrm{BAF} 60 \mathrm{C}=$ a subunit of chromatin-remodelling complex BAF; SMYD1= histone methyltransferase.

\section{References}

[1] Hoffman J I, KaplanS. The incidence of congenital heart disease, J Am Coll Cardiol .2002 ;39:1890-1900.

[2] V.Garg. Insights into the genetic basis of congenital heart disease,Cell. Mol. Life Sci. 2006; 63(10):1141-1148.

[3] Kohl HW 3rd.Rubella screening and vaccination follow-up by a hospital employee health office, Am J Infect Control. 1985;13(3):124-7.

[4] Singh M, Shah GL, Singh KP. Teratogenic effects of dilantin on thoraco-abdominal organs of developing chick embryos, Indian J Exp Biol. 2000;38(10):1026-30.

[5] Dawson BV, Johnson PD, Goldberg SJ, et al. Cardiac teratogenesis of halogenated hydrocarbon-contaminated drinking water, J Am Coll Cardiol. 1993 ;21(6):1466-72.

[6] Kumar SD, Dheen ST, Tay SS. Maternal diabetes induces congenital heart defects in mice by altering the expression of genes involved in cardiovascular development, Cardiovasc Diabetol.2007;6:34.

[7] McCart A, Latchford A, Volikos E, et al. A novel exon duplication event leading to a truncating germ-line mutation of the APC gene in a familial adenomatous polyposis family.Fam Cancer. 2006;5(2):205-8.

[8] Kakavas VK, Plageras P, Vlachos TA, et al. PCR-SSCP: a method for the molecular analysis of genetic diseases. Mol Biotechnol. 2008;38(2):155-63.

[9] Moorman AF, Christoffels VM. Cardiac chamber formation: development, genes, and evolution. Physiol Rev. 2003; 83 (4): 1223-1267.

[10] Michael E. Mitchell, Tara L, et al. The molecular basis of congenital heart disease. Semin Thorac Cardiovasc Surg. 2007 ; 19 (3):228-237.

[11] Dunwoodie SL. Combinatorial signaling in the heart orchestrates cardiac induction, lineage specification and chamber formation. Semin Cell Dev Biol. 2007;18(1):54-66.

[12] Brand T. Heart development: molecular insights into cardiac specification and early morphogenesis. Dev Biol. 2003;258 (1):1-19.

[13] Gruber PJ, Epstein JA. Epstein. Development gone awry congenital heart disease. Circ Res. 2004;94 (3):273-283.

[14] Grego-Bessa J, Luna-Zurita L, del Monte G, et al. Notch signaling is essential for ventricular chamber development. Dev Cell . 2007;12:415-429.

[15] Risebro CA, Riley PR. Formation of the ventricles. Scientific World Journal. $2006 ; 6: 1862-$ 80.

[16] Cohen ED, Tian Y, Morrisey EE. Wnt signaling: an essential regulator of cardiovascular differentiation, morphogenesis and progenitor self-renewal. Development. 2008;135(5):789-98. 
[17] Xiao H, Zhang YY. Understanding the role of transforming growth factor-beta signalling in the heart: overview of studies using genetic mouse models. Clin Exp Pharmacol Physiol.2008;35(3):335-41.

[18] Moon JI, Birren SJ. Target-dependent inhibition of sympathetic neuron growth via modulation of a BMP signaling pathway. Dev Biol. 2008; 315(2):404-17.

[19] Mjaatvedt CH, Nakaoka T, Moreno-Rodriguez R, et al. The outflow tract of the heart is recruited from a novel heart-forming field. Dev. Biol. 2001; 238 (1): 97-109.

[20] Bruneau BG. The developmental genetics of congenital heart disease.Nature. 2008; 451(7181):943-8.

[21] High FA, Epstein JA. The multifaceted role of Notch in cardiac development and disease. Nat Rev Genet. 2008;9(1):49-61.

[22] Armstrong EJ, Bischoff J. Heart valve development: endothelial cell signaling and differentiation. Circ Res. 2004;3;95(5):459-70.

[23] Yutzey KE, Colbert M, Robbins J. Ras-related signaling pathways in valve development:ebb and flow. Physiology (Bethesda). 2005 ;20:390-7.

[24] Joziasse IC, van de Smagt JJ, Smith K, et al. Genes in congenital heart disease: atrioventricular valve formation. Basic Res Cardiol. 2008;103(3):216-27.

[25] Pierpont ME, Basson CT, Benson DW, et al. Genetic basis for congenital heart defects: current knowledge: a scientific statement from the American Heart Association Congenital Cardiac Defects Committee, Council on Cardiovascular Disease in the Young: endorsed by the American Academy of Pediatrics. Circulation. 2007;115:3015-3038.

[26] Ikeda Y, Hiroi Y, Hosoda T, et al. Novel point mutation in the cardiac transcription factor CSX/NKX2.5 associated with congenital heart disease. Circ J. 2002;66:561563.

[27] McElhinney DB, Geiger E, Blinder J, et al. NKX2.5 mutations in patients with congenital heart disease. J Am Coll Cardiol. 2003;42:1650 -1655.

[28] Elliott DA, Kirk EP, Yeoh T, et al. Cardiac homeobox gene NKX2-5 mutations and congenital heart disease: associations with atrial septal defect and hypoplastic left heart syndrome. J Am Coll Cardiol. 2003;41:2072-2076.

[29] Schubbert S, Zenker M, Rowe SL, et al. Germline KRAS mutations cause Noonan syndrome. Nat Genet. 2006;38:331-336.

[30] Tartaglia M, Kalidas K, Shaw A, et al. PTPN11 mutations in Noonan syndrome: molecular spectrum, genotype-phenotype correlation, and phenotypic heterogeneity. Am J Hum Genet. 2002;70:1555-1563.

[31] Toko H, Zhu W, Takimoto E, et al. Csx/Nkx2-5 Is Required for Homeostasis and Survival of Cardiac Myocytes in the Adult Heart. J Biol Chem. 2002;277(27):24735-43.

[32] Akazawa H, Komuro I. Cardiac transcription factor Csx/Nkx2-5: Its role in cardiac development and diseases. Pharmacol Ther.2005;107(2):252-68.

[33] Goldmuntz E, Bamford R, Karkera JD, et al. CFC1 mutations in patients with transposition of the great arteries and double-outlet right ventricle. Am J Hum Genet. 2002;70(3):776-80.

[34] Davit-Spraul A, Baussan C, Hermeziu B, et al. CFC1 gene involvement in biliary atresia with polysplenia syndrome. J Pediatr Gastroenterol Nutr. 2008;46(1):111-2. 
[35] Muncke N, Jung C, Rüdiger $H$, et al. Missense mutations and gene interruption in PROSIT240, a novel TRAP240-like gene, in patients with congenital heart defect (transposition of the great arteries). Circulation. 2003;108(23):2843-50.

[36] Finelli P, Pincelli AI, Russo S, et al. Disruption of friend of GATA 2 gene (FOG-2) by a de novo $\mathrm{t}(8 ; 10)$ chromosomal translocation is associated with heart defects and gonadal dysgenesis. Clin Genet. 2007;71(3):195-204..

[37] Heritage ML, MacMillan JC, Anderson GJ. DHPLC mutation analysis of Jagged1 (JAG1) reveals six novel mutations in Australian alagille syndrome patients. Hum Mutat. 2002;20(6):481.

[38] Robinson SW, Morris CD, Goldmuntz E, et al. Missense mutations in CRELD1 are associated with cardiac atrioventricular septal defects. Am J Hum Genet. 2003;72(4):1047-52

[39] Tomita-Mitchell A, Maslen CL, Morris CD, et al. GATA4 sequence variants in patients with congenital heart disease. Eur J Med Genet. 2008;51(6):527-35.

[40] Zhu L, Zhou G, Poole S, et al. Characterization of the interactions of human ZIC3 mutants with GLI3. Hum Mutat. 2008;29(1):99-105.

[41] Harrison CA, Gray PC, Fischer WH, et al. An activin mutant with disrupted ALK4 binding blocks signaling via type II receptors. J Biol Chem. 2004;279(27):28036-44.

[42] Besser D. Expression of nodal, lefty-a, and lefty-B in undifferentiated human embryonic stem cells requires activation of Smad2/3. J Biol Chem. 2004;279(43):45076-84.

[43] Ferland RJ, Gaitanis JN, Apse K, et al. Periventricular nodular heterotopia and Williams syndrome. Am J Med Genet A. 2006;140(12):1305-11.

[44] Fan C, Liu M, Wang Q. Functional analysis of TBX5 missense mutations associated with Holt-Oram syndrome. J Biol Chem.2003;278(10):8780-5.

[45] Zhao F, Weismann CG, Satoda M, et al. Novel TFAP2B mutations that cause Char syndrome provide a genotype-phenotype correlation. Am J Hum Genet. 2001;69(4):695-703.

[46] Ko JM, Kim JM, Kim GH, et al. PTPN11, SOS1, KRAS, and RAF1 gene analysis, and genotype-phenotype correlation in Korean patients with Noonan syndrome. J Hum Genet. 2008;53(11-12):999-1006.

[47] Roberts AE, Araki T, Swanson KD, et al. Germline gain-of-function mutations in SOS1 cause Noonan syndrome. Nat Genet. 2007;39(1):70-4.

[48] Wincent J, Holmberg E, Strömland K, et al. CHD7 mutation spectrum in 28 Swedish patients diagnosed with CHARGE syndrome. Clin Genet. 2008;74(1):31-8.

[49] Temtamy SA, Aglan MS, Valencia M, et al. CHD7 mutation spectrum in 28 Swedish patients diagnosed with CHARGE syndrome. Hum Mutat. 2008;29(7):931-8.

[50] Ulucan H, Gül D, Sapp JC, et al. Extending the spectrum of Ellis van Creveld syndrome: a large family with a mild mutation in the EVC gene. BMC Med Genet. 2008;9:92

[51] Li D, Yu J, Gu F, et al. The roles of two novel FBN1 gene mutations in the genotypephenotype correlations of Marfan syndrome and ectopia lentis patients with marfanoid habitus. Genet Test. 2008;12(2):325-30. 
[52] Singh KK, Rommel K, Mishra A, et al. TGFBR1 and TGFBR2 mutations in patients with features of Marfan syndrome and Loeys-Dietz syndrome. Hum Mutat. 2006;27(8):770-7.

[53] Niihori T, Aoki Y, Narumi Y, et al. Germline KRAS and BRAF mutations in cardiofacio-cutaneous syndrome. Nat Genet. 2006;38(3):294-6.

[54] Roberts A, Allanson J, Jadico SK, et al. The cardiofaciocutaneous syndrome.J Med Genet. 2006 Nov;43(11):833-42.

[55] Nava C, Hanna N, Michot C, et al. Cardio-facio-cutaneous and Noonan syndromes due to mutations in the RAS/MAPK signalling pathway: genotype-phenotype relationships and overlap with Costello syndrome. J Med Genet. 2007;44(12):76371.

[56] Quezada E, Gripp KW. Costello syndrome and related disorders.Curr Opin Pediatr. 2007;19(6):636-44.

[57] Clark EB. Mechanisms in the pathogenesis of congenital heart disease. In: Pierpont ME, Moller J, editors. The genetics of cardiovascular disease. Boston, MA' MartinusNijoff; 1986. p. $3-11$.

[58] Clark EB. Pathogenetic mechanisms of congenital cardiovascular malformations revisited. Semin Perinatol 1996;20:465- 72.

[59] Benoit G. Bruneau. The developmental genetics of congenital heart disease. Nature. 2008;451(7181):943-8.

[60] Hyun C, Lavulo L. Congenital heart diseases in small animals: Part I. Genetic pathways and potential candidate genes. The Veterinary Journal; 2006; 171 (2): 245-255.

[61] Hiroi Y, Kudoh S, Monzen K, et al. Tbx5 associates with Nkx2-5 and synergistically promotes cardiomyocyte differentiation. Nat. Genet. 2001;28 (3): 276-280.

[62] Goldmuntz E, Geiger E, Benson DW. NKX2.5 mutations in patients with tetralogy of fallot. Circulation. $2001 ; 104$ (21): 2565-2568.

[63] Stennard FA, Costa MW, Elliott DA, et al. Cardiac T-box factor Tbx20 directly interacts with Nkx2-5, GATA4, and GATA5 in regulation of gene expression in the developing heart. Dev Biol. 2003 ;262(2):206-24.

[64] Pashmforoush M, Lu JT, Chen H, et al. Nkx2-5 pathways and congenital heart disease: loss of ventricular myocyte lineage specification leads to progressive cardiomyopathy and complete heart block. Cell .2004; 117 (3): 373-386.

[65] Pu WT, Ishiwata T, Juraszek AL, et al. GATA4 is a dosage-sensitive regulator of cardiac morphogenesis. Dev. Biol. 2004 ; 275 (1): 235-244.

[66] Moskowitz IP, Kim JB, Moore ML, et al. A molecular pathway including Id2, Tbx5, and Nkx2-5 required for cardiac conduction system development. Cell. 2007;129(7):136576.

[67] Ching YH, Ghosh TK, Cross SJ, et al. Mutation in myosin heavy chain 6 causes atrial septal defect. Nat. Genet. 2005;37 (4): 423-428.

[68] Varadkar P, Kraman M, Despres D, et al. Notch2 is required for the proliferation of cardiac neural crest-derived smooth muscle cells. Dev Dyn. 2008;237(4):1144-52.

[69] Del Monte G, Grego-Bessa J, González-Rajal A, et al. Monitoring Notch1 activity in development: evidence for a feedback regulatory loop. Dev Dyn. 2007;236(9):2594614 . 
[70] Kwon C, Arnold J, Hsiao EC, et al. Canonical Wnt signaling is a positive regulator of mammalian cardiac progenitors. Proc Natl Acad Sci U S A.2007;104(26):10894-9.

[71] Miller CT, Swartz ME, Khuu PA, et al. mef2ca is required in cranial neural crest to effect Endothelin1 signaling in zebrafish. Dev Biol. 2007;308(1):144-57.

[72] Ren X, Li Y, Ma X, et al. Activation of p38/MEF2C pathway by all-trans retinoic acid in cardiac myoblasts. Life Sci. 2007;81(2):89-96.

[73] Ueno S, Weidinger G, Osugi T, et al. Biphasic role for Wnt/beta-catenin signaling in cardiac specification in zebrafish and embryonic stem cells. Proc Natl Acad Sci U S A. 2007;104(23):9685-90.

[74] Groenendijk BC, Stekelenburg-de Vos S, Vennemann P, et al. The endothelin-1 pathway and the development of cardiovascular defects in the haemodynamically challenged chicken embryo. J Vasc Res. 2008;45(1):54-68.

[75] Couzin J. Breakthrough of The Year: Small RNAs make big splash, Science. 2002 ; 298 (5602):2296-2297.

[76] Liu CG, Calin GA, Meloon B, et al. An oligonucleotide microchip for genome-wide microRNA profiling in human and mouse tissues. Proc Natl Acad Sci U $S$ A. 2004;101(26):9740-4.

[77] Lee CT, Risom T, Strauss WM. MicroRNAs in mammalian development. Birth Defects Res C Embryo Today. 2006 ; 78 (2):129-139.

[78] Zhang B, Wang Q, Pan X. MicroRNAs and their regulatory roles in animals and plants, J Cell Physiol .2007 ; 210 (2): 279-289.

[79] Zhao Y. Ransom JF, Li A, et al. Dysregulation of cardiogenesis, cardiac conduction, and cell cycle in mice lacking miRNA-1-2. Cell. 2007 ; 129 (2):303-317.

[80] Zhao Y, Samal E, Srivastava D. Serum sponse factor regulates a muscle-specific microRNA that targets Hand2 during cardiogenesis, Nature.2005 ; 436 (7048):214220.

[81] Kwon C, Han Z, Olson EN, et al. MicroRNA1 influences cardiac differentiation in Drosophila and regulates Notch signaling, Proc Natl Acad Sci USA. 2005 ; 102 (52):18986-18991.

[82] Wong AH, Gottesman II, Petronis A. Phenotypic differences in genetically identical organisms: the epigenetic perspective. Human Molecular Genetics, 2005, 14(1):R11R18.

[83] Armstrong L, Lako M, Dean W, et al. Epigenetic modification is central to genome reprogramming in somatic cell nuclear transfer. Stem Cells.2006; 24(4):805-814.

[84] Jacinto FV, Esteller M, Mutator pathways unleashed by epigenetic silencing in human cancer. Mutagenesis. 2007;22(4):247-53.

[85] Warnes CA. The adult with congenital heart disease: Born to be bad? J Am Coll Cardiol. 2005;46:1-8.

[86] Cambien F, Tiret L, Genetics of cardiovascular diseases: from single mutations to the whole genome. Circulation,2007;116;1714-1724 .

[87] Gatzoulis MA. Adult congenital heart disease: a cardiovascular area of growth in urgent need of additional resource allocation. Int. J. Cardiol. 2004 ; 97 (Suppl 1): 12.

[88] Cohen JC. Genetic approaches to coronary heart disease. J Am Coll Cardiol. 2006;48:A10A14. 
[89] Wallace C, Newhouse SJ, Braund P, et al. Genomewide association study identifies genes for biomarkers of cardiovascular disease: serum urate and dyslipidemia. Am J Hum Genet. 2008; 82:139-149.

[90] Todd AK. Bioinformatics approaches to quadruplex sequence location. Methods .2007;43(4):246-251.

[91] Yang W, Paschen W. Conditional gene silencing in mammalian cells mediated by a stress-inducible promoter. Biochem Biophys Res Commun. 2008;365(3):521-7. 


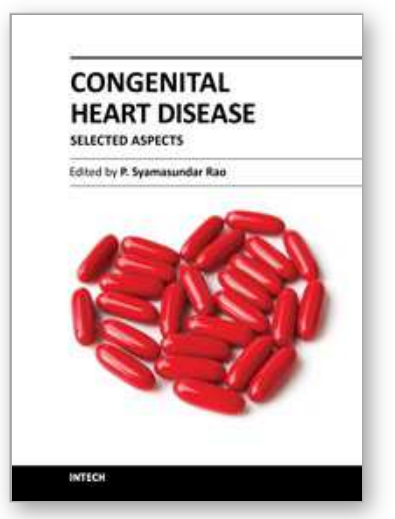

\author{
Congenital Heart Disease - Selected Aspects \\ Edited by Prof. P. Syamasundar Rao
}

ISBN 978-953-307-472-6

Hard cover, 348 pages

Publisher InTech

Published online 18, January, 2012

Published in print edition January, 2012

There are significant advances in the understanding of the molecular mechanisms of cardiac development and the etiology of congenital heart disease (CHD). However, these have not yet evolved to such a degree so as to be useful in preventing $\mathrm{CHD}$ at this time. Developments such as early detection of the neonates with serious heart disease and their rapid transport to tertiary care centers, availability of highly sensitive noninvasive diagnostic tools, advances in neonatal care and anesthesia, progress in transcatheter interventional procedures and extension of complicated surgical procedures to the neonate and infant have advanced to such a degree that almost all congenital cardiac defects can be diagnosed and "corrected". Treatment of the majority of acyanotic and simpler cyanotic heart defects with currently available transcatheter and surgical techniques is feasible, effective and safe. The application of staged total cavo-pulmonary connection (Fontan) has markedly improved the long-term outlook of children who have one functioning ventricle. This book, I hope, will serve as a rich source of information to the physician caring for infants, children and adults with CHD which may help them provide optimal care for their patients.

\title{
How to reference
}

In order to correctly reference this scholarly work, feel free to copy and paste the following:

Jing-bin Huang and Jian Liang (2012). Molecular Mechanisms of Congenital Heart Disease, Congenital Heart Disease - Selected Aspects, Prof. P. Syamasundar Rao (Ed.), ISBN: 978-953-307-472-6, InTech, Available from: http://www.intechopen.com/books/congenital-heart-disease-selected-aspects/molecular-mechanisms-ofcongenital-heart-disease

\section{INTECH}

open science | open minds

\section{InTech Europe}

University Campus STeP Ri

Slavka Krautzeka 83/A

51000 Rijeka, Croatia

Phone: +385 (51) 770447

Fax: +385 (51) 686166

www.intechopen.com

\section{InTech China}

Unit 405, Office Block, Hotel Equatorial Shanghai

No.65, Yan An Road (West), Shanghai, 200040, China 中国上海市延安西路65号上海国际贵都大饭店办公楼 405 单元

Phone: +86-21-62489820

Fax: $+86-21-62489821$ 
(C) 2012 The Author(s). Licensee IntechOpen. This is an open access article distributed under the terms of the Creative Commons Attribution 3.0 License, which permits unrestricted use, distribution, and reproduction in any medium, provided the original work is properly cited. 